\title{
Correction to: Telemedicine in general neurology: use of audiovisual consultation for on call back-up service in an acute care hospital
}

\author{
Frank Janssen ${ }^{1} \cdot$ Mohammed Awadallah $^{1} \cdot$ Awed Alhalabi $^{1} \cdot$ Barbara Körber $^{2} \cdot$ Reinhard Lang $^{3} \cdot$ Mateusz Scibor $^{4}$. \\ René Handschu ${ }^{1}{ }^{\circledR}$
}

Published online: 25 June 2019

(c) Springer-Verlag GmbH Germany, part of Springer Nature 2019

\section{Correction to: Journal of Neurology (2018) 265:880-884 https://doi.org/10.1007/s00415-018-8756-4}

The original version of this article unfortunately contained a mistake in the acknowledgement section.

Please find the corrected Acknowledgements here:

\section{Acknowledgements}

The present work was performed in fulfillment of the requirements for obtaining the degree "Dr. med." at the Friedrich-Alexander-Universitaet Erlangen-Nuernberg (FAU).

We are very grateful to Sonia Heinloth for proof-reading the manuscript.
The original article can be found online at https://doi.org/10.1007/ s00415-018-8756-4.

René Handschu

rene.handschu@klnikum.neumarkt.de

1 Department of Neurology, Klinikum Neumarkt, Nürnberger Str. 12, 92318 Neumarkt/Opf, Germany

2 Emergency Department, Klinikum Neumarkt, Neumarkt/Opf, Germany

3 Department of Information Technology, Klinikum Neumarkt, Neumarkt/Opf, Germany

4 Department of Neurology/STENO Network,

Friedrich-Alexander-Universitaet Erlangen-Nuernberg, Erlangen, Germany
Also, the affiliation of author Mateusz Scibor contained a mistake: The correct affiliation is Friedrich-AlexanderUniversitaet Erlangen-Nuernberg. 